\title{
Social Systems in Higher Education: Collectivities and Technology
}

\section{Lucille B. Mazo}

MacEwan University, Canada.

\begin{abstract}
This study investigates the core concepts and views that underlie the theories of social systems as explained by four theorists. It critically assesses and analyzes the role of the higher education system within society, as well as the role of the educator within this social system as defined and articulated by Durkheim (1956), outlined and explained from a hierarchical perspective by Parsons (1951), identified as an integrative process by Bertalanffy (1968), and viewed as a web of relationships by Capra (1996). Major themes from each theorist are analyzed with respect to what role social systems play in higher education and how educators are affected by internal social subsystems and collectivities. An example is presented on how collectivities exist online and use technology to continue at a university during the COVID-19 pandemic.
\end{abstract}

Keywords: Social systems; higher education; collectivities; technology; autopoiesis. 


\section{Introduction}

Synthesis of four seminal systems theorists is crucial to understanding the relationships between social systems and higher education institutions as they are formed and applied as collectivities. Comprehensive analysis of Durkheim's (1956), Parsons' (1951), Bertalanffy's (1968), and Capra's (1996) approaches to and explanations of social systems provides critical information about the role that a higher education institution plays within society as a whole, as well as the role that the educator fulfills within its academic community. In relation to the COVID-19 pandemic, the shift of social systems from in-person to online learning in the form of classes, meetings, and collaborative decision-making, the creation of groups or collectivities of professors and students have continued due to innovative technology.

\section{Social Systems and Higher Education}

Pondering, exploring, and examining in-depth the profound question of how life exists within a social system, and drawing from the perspectives of their specific disciplines, Durkheim (1956), Parsons (1951), Bertalanffy (1968), and Capra (1996) observed and recognized the need to understand life's underlying substance and form, which resulted in the development of their corresponding systems theories. Each theorist sought to identify the fundamental structures and patterns that comprise the network of systems visible within society. And, each theorist presented one or more pieces of crucial information that advanced the field of systems thinking. As systems thinkers, they understood the theory of social systems and its impact on education. In varying degrees and levels of comprehension, they articulated the role that the concepts of pattern, organization, wholeness, and relationships played within educational social systems, including academic collectivities. Higher education provides critical collectivies that have been established traditionally, such as in-person classes, seminars, and discussion groups that include professors and students. However, with the creation of online learning collectivities that have developed as a result of the pandemic, these traditional social structures are being reassessed within the context of innovative online learning technology such as livestreaming.

\subsection{Theorists - Conscience Collective}

Durkheim (1956) examined how the institution of education had influenced society. $\mathrm{He}$ introduced the concept of the group mind or "conscience collective" which viewed human minds as one holistic thought pattern (p. 8). Unlike Durkheim, Parsons (1951) focused on "institutionalized roles and the motivational processes organized about them" (p. vii). $\mathrm{He}$ observed how societal evolution had shaped social systems, their structures, and their functions, and argued that a social system required a written language in order to continue to evolve (1985, p. 69). Education fulfilled this important linguistic role in developing social systems. He applied the theory of functionalism in his explanation of his social system theory, 
viewing society as an assembly of hierarchical systems, subsystems, and individuals who performed various functions. He, also, introduced the concept of "collectivities" which he defined as societies of individuals found within a social system (1951, p. 394). However, Parsons' approach was generally mechanistic and focused on the roles and functions of the parts within the hierarchy of a social system. His work included minimal discussion with regards to viewing the system as a whole rather than a collection of parts and how the interrelationships between these parts were critical in establishing the system's form or pattern. Yet, Parsons' work was an example of how the gradual shift from the mechanistic to the systems thinking approach began to occur during the twentieth century. "The shift from function to organization represented a shift from mechanistic to systemic thinking, because function was essentially a mechanistic concept" (Capra, 1996, p. 27). This paradigm shift was fundamentally advanced when Bertalanffy (1968) proposed his seminal model of "open systems" which defined and outlined a framework of organization common to all living systems (p. 43).

\subsection{Theorists - Open Systems}

Bertalanffy's (1968) “open systems" model created significant discussion within the disciplines of biology, psychology, and physics. His concept of Unity through Diversity was published in his two-volume book Festschrift (p. 8). He proposed that living systems dynamically exchanged materials and resources between their internal and external environments. His theory also considered the interchange that occurred between other systems, suggesting that a system maintained a constant "steady state" within its boundaries by using these continual exchanges to support the integrity of the system. Without these exchanges, the system would become stagnant and compromise its ability to exist. His "open systems" view countered the "closed" systems view that was currently held by physicists who believed that a system functioned independently of others and was in a state of equilibrium where no dynamic exchanges occurred. Bertalanffy argued that living systems must remain open to actively receive materials or they would potentially expire. University online learning classes or collectivities of students and professors are an example of Bertalanffy's open system model, which allows for participants to exchange knowledge and information as a collective whole. Professors and students establish an online framework for the class by using learning technology (e.g. e-Class) that offers visual and verbal cues for learning, discussion, and social connection. The exchange of knowledge, the establishment of a learning framework using online learning technology, and the social connection provided through livestreaming can be applied to maintain a constant steady state within the boundaries of the online course. 


\subsection{Theorists - Ecosystems}

More recently, however, Capra (1996) added to this knowledge base by describing life systems as a web or network of interrelated "relationships." He viewed communities and societies as "ecosystems," which to the author were similar to what Parsons (1951) defined as "collectivities," a compilation of societies within a social system (p. 394). However, dissimilar to Parsons' focus on function and structure, Capra emphasized the importance of understanding the substance and form of a social system by examining the comprehensive integration of its parts and the interrelationships between them. "The behavior of every living member of the ecosystem depended on the behavior of many others. The success of the whole community depended on the success of its individual members, while the success of each member depended on the success of the community as a whole" (p. 298). He presented the concept of "deep ecology" which meant that all communities as social systems needed to follow the basic principles of ecology so that they could realign their system values within them-interdependence, recycling, partnership, flexibility, and diversity (p. 304). Higher education institutions epitomize deep ecology in their structure and form. Online learning technology has provided innovative methods and approaches to support the deep ecology of collectivities within universities by enabling classes, student groups, university wide decision councils, and symposiums to continue within the structure and form of these social systems with the aim of minimizing the disruption to these academic communities.

\section{Educator's Role in the Higher Education Social System - Collectivities}

The educator's role in the higher education social system is critical to the success of a university and fulfills an important part of this holistic system. What effect does the social system of a university have on the educator's role? How critical is the educator's role in sustaining the steady state of relationships that exist within and outside of the social systems and subsystems of a university? How has innovative online technology supported these systems, as university professors are being faced with shifting and rethinking their approaches to virtual teaching, learning, and decision-making situations as a result of the pandemic?

\subsection{University Open Social System}

The university social system is essentially an open system, exchanging knowledge, materials, and resources within its boundaries and sharing this information with those social systems located within external communities. Within this system, educators act both individually and collectively to respond to the demands of research, teaching, and service workloads, and to establish interrelationships with local groups. The interchange of information between the university and the external community is one example of what identifies it as an open system and which also allows for the educator's role to become a critical part of the university social 
system. As a result of this exchange, the educator is able to fulfill both the self-orientation and collectivity-orientation needs within the university. For example, two or more individual educators are required to form groups or "collectivities" (Parsons, 1951, p. 142) within a university. Assembling a critical mass of educators who are experts in their field would create a foundational collectivity where their wisdom could be applied when discussing the university's internal and external institutional challenges. This type of collectivity would comprise discipline-based specialists who would contribute their specialized knowledge to assist in resolving issues. However, it is important to note that while they are restricted in their contributions relative to the questions allowed by their disciplines, any involvement in solving an issue would be viewed as a gesture of collaboration and cooperation.

\subsection{University Collectivities}

While Parsons (1951) did not discuss whether this type of collectivity was closed or open in its form and substance, Bertalanffy (1968) would have argued that it was an open system, even though it may have appeared to be a closed system based on the fact that its internal social structure or hierarchy consisted of all university professors deriving from only one sector of society. Closer inspection of this collectivity would have revealed that there was a dynamic exchange of information and resources between the university professors who strove to maintain a steady state while completing their work. Hence, an open system may not always be obvious or evident to external viewers, especially if it is based on minimal knowledge about the collectivity's activities. However, the existence of this type of collectivity could potentially be in jeopardy at some stage, because of the lack of external resources accessible to its growth and success. To remedy this situation, the collectivity could also include individuals who were external to the university's social system, such as professional engineers, medical doctors, or artists who could contribute to the solution of the problem. The constant influx of professional experts from various disciplines would provide a steady state of new knowledge and perspectives from which the collectivity would use to support its long-term continued existence within the social system of a higher education institution. As a result of combining these two groups of authorities within society, problems would be approached from a broader spectrum of knowledge, allowing educators as participants of the university social system to achieve solutions from a holistic perspective. An academic symposium, conference, or special interest group are examples of how university professors collectively gather to exchange their knowledge, information, experience, and connections with other academics (local, national, international), and with community groups such as charitable organizations, artists, businesses, governments (e.g. UNESCO). 


\subsection{University Collectivity of Professors}

In addition to these external individuals providing a constant input of resources, the university collectivity of professors could improve the flow of information and materials by soliciting feedback from the greater external community. Additional resources from various other collectivities within the broader community would provide sources of knowledge and practical experience that could potentially influence the decision-making processes of an educator both as a professor in the classroom and as a member of a committee. Any information that was not relevant to the collectivity and its decisions would be accepted or rejected based on the collectivity's needs. Depending on the type of problem that required a solution, potential examples of greater external collectivities would include the chamber of commerce, police stations, financial institutions, medical clinics, education board of trustees, theatrical companies, and ecological organizations. As an open social system, the collectivity of university professors would maintain their presence both within the university as well as in the professional and greater external communities. If Parsons (1951) viewed education as a series of collectivities supported by hierarchical levels, and Bertalanffy (1968) viewed higher education as being integrative and open in its exchange of information and resources, how did Capra (1996) view a university's social system and its effect on the educator's role?

\subsection{University as an Organized Whole - Autopoiesis}

Capra (1996) argued that humankind needed to reconnect with the other communities that comprise the web of life. Similar to Bertalanffy's (1968) concept of a "steady state," Capra recognized that the importance of creating and maintaining sustainable communities was critical to developing hierarchy and organization within social systems. His idea of the collective human spirit as being one part of the whole within a societal collectivity coincided with Durkheim's (1956) concept of the "conscience collective." Based on his concept, Durkheim's perspective on education was that of a "system of ideas, sentiments and tendencies which express in us, not our personality, but the group or different groups of which we are part" (p. 29).

Hence, is it possible for a university to achieve a "steady state," "an organized whole," or an established "ecosystem" within its social system boundaries? The concept of deep ecology is the embodiment of a systems theory where a university social system could achieve its numerous goals at many levels. If the university stakeholders were willing to understand, accept, and implement this concept within a higher education environment, then Parsons' (1951) concepts of universalism-particularism and institutional types, and Bertalanffy's (1968) open systems theory would be integrated into what Capra describes as a "web of life," the "whole," and the "ecological worldview" approaches to systems. "Autopoiesis" is one such view that has been presented which explains how the substance (matter, structure, quantity) and form (pattern, order, quality) of an object are considered as a combined system 
rather than ones that are separate. Capra (1996) agreed with Maturana's and Varela's concept of autopoiesis, or "self-making" which made "it possible to integrate structure-oriented models of self-organization" (as cited in Capra, p. 99). As a result of this concept, both mechanistic and systems thinking approaches to living systems were combined, bridging the chasm that had existed between these two systems approaches. Capra further explained that the organization of a living system was based on the relationships between the components that identified it within a general class (e.g. committee). The structure of a living system was based on the relationships between the components that it constituted which defined the specific type or kind of organization within this class (e.g., Curriculum, Sustainability, Student Success). Therefore, the organization of a living system was supported by all of the components that were found internally and that were continually being replenished by new resources from the external environment. Bertalanffy's (1968) open systems theory supported this concept.

In relation to higher education, the concept of autopoiesis can be applied in several ways and at various levels of a university's organization. A university is self-making in that its overall organization is sustained by a general pattern of internal collectivities and communities of educators that are present within its academic social system. The descriptions of the relations between these groups are fundamental to maintaining the university's organizational form. For example, in order for a university to function, it must include a general set of relations that meet the criteria of what constitutes a university. The required collectivities and academic social communities located within a university create the general organization of an academic social system. Therefore, collectivities such as the finance, registrar, and academic affairs departments, and academic communities such as the faculty association, curriculum committees, and general faculties council are the general descriptions of classes located within the social system of a university. The relations between these classes create the organization of the university. The structure of a university is developed through the relationships that are found within these classes or departments. As an example, the Registrar department constitutes many components within its class boundaries: staff members, administration, information technology, academic policy, tuition fees, and integrity officer. The relations between each of these components constitute the substance or structure of a university.

Autopoiesis is also evident in the increasing number of programs that have arisen within universities that address integrative education. Programs such as Women's Integrative Studies, and Communications Interdisciplinary Studies are self-making and self-regulating in that they offer comprehensive discourse and integrative teaching that reach into the combined disciplines, providing flexibility throughout the program of study. This deep ecological approach to education supports Capra's (1996) web of life concept where networks within networks of knowledge are leveraged to sustain the insatiable curiosity of 
researchers, educators, and students engaged in learning (p. 99). The in-depth overlapping of information, experience, and wisdom creates a multi-layered and multifaceted understanding that is based on the whole.

\subsection{Establishing an Online University Collectivity-International Education Departmemt}

MacEwan University's International Education department is mandated with establishing connections with other universities globally by signing a memorandum of understanding (MOU) with universities that have similar programming so that student exchange, faculty visiting scholars, and international research projects are created. Prior to the COVID-19 pandemic, students and faculty travelled abroad to participate in these teaching, learning, and research opportunities. However, the travel and health restrictions in many countries have limited and/or closed these opportunities of collaboration between the professor and student collectivies that would otherwise occur in-person. In many situations, these exchanges have continued due to the innovative technology that is available for students to continue to learn and interact with students and professors from other countries and cultures. Livestreaming lectures and discussion groups have enabled students and professors to continue crosscultural sharing of knowledge. While this learning does not replace the in-person experience of a culture, the technology has provided the two collectivities (students and professors), as well as the two universities participating in the MOU to continue their exchange of knowledge as an open social system.

\section{Conclusion}

While the analysis of Durkheim's (1956), Parsons' (1951), Bertalanffy's (1968), and Capra's (1996) theories, philosophies, and concepts of systems thinking has revealed similarities and differences in their approaches, all four theorists added their knowledge and insight to how social systems, higher education, and educators are interrelated. The social system and subsystems of a university are a complex set of relationships that support the dynamics between the systems and the educators who perform within these systems. Each relationship, individual or group, assists in establishing the patterns that constitute a university's social system. The university contains a plethora of collectivities or ecosystems that support this dynamic exchange between its internal and external form and substance, each interdependent in its role. The roles of higher education and the educator continue to affect the conditions within their own and other social systems. As such, systems thinkers will continue to research the complexities of social systems and higher education and their enduring relationships. 


\section{References}

Bertalanffy, L. V. (1968). General systems theory: Foundations, development, applications. New York: G. Braziller.

Capra, F. (1996). The web of life: A new scientific understanding of living systems. New York: Anchor.

Durkheim, E. (1956). Education and sociology. Simon \& Shuster.

Parsons, T. (1985). Talcott Parsons on institutions and social evolution (Ed. Leon H. Mayhew). Chicago, IL: University of Chicago Press.

Parsons, T. (1951). The social system. Cambridge, MA: Harvard University Press.

Stanford Encyclopedia of Philosophy (2009). "Functionalism.” Retrieved March 10, 2020, from http://plato.stanford.edu/entries/functionalism/\#RolFunReaFun 